only one available without risking the life of the young person, but in lesser cases there will be increasing room for debate on this question.

In conclusion, practitioners are advised to proceed cautiously in treating children and young people whose consent is in doubt. Given the anomalies, seeking legal advice may well be appropriate in difficult cases, particularly when a young person withholds consent and serious consequences, including death, may ensue unless treatment is forthcoming. Individual cases may need to be brought before the High Court so that the option of lifesaving treatment can be debated in full.

1 The Children Act 1989. London: HMSO, 1989.

2 Gillick $v$ West Norfolk and Wisbech Area Health Authority, 19861 Appeal Cases 112-207.

3 Department of Health. The Children Act 1989: guidance and regulations. Vol 4. Residential care. London: HMSO, 1991.

4 Jones DPH. Working with the Children Act: tasks and responsibilities of the child and adolescent psychiatrist. In: Lindsey C, ed. Proceedings of the Children Act course. London: Royal College of Psychiatrists, 1991:23-41. (Occasional paper series.)

$5 \operatorname{Re} \mathrm{R}(1991)$ Weekly Law Repons 3,592-608.

$6 \mathrm{Re} W(1992)$ Weekly Law Reports 3,758-82.
7 Deeprose M. Children's consent is a law unto itself. BMA News Review 1992; 18:19-20.

8 Anonymous. Medical treatment. Longman Practitioner's Child Law Bulletin 1992;5(2):87-9.

9 The Family Law Reform Act 1969. London: HMSO, 1969.

10 Eekelaar JM. The emergence of children's rights. Oxford fournal of Legal Studies 1986;6:161-82.

11 Lowe NV, White R. Wards of Cour. 2nd ed. London: Barry Rose, 1986:132

$12 \operatorname{Re} X$ (1975) Family Division 47-62.

12 Re X (1975) Family Division 47-62.

14 Black D. Age of consent except when over-ridden. Health and Social Service fournal 1979 Mar 22: 208 .
fol

15 Roth LH, Meisel A, Lidz CW. Tests of competency to consent to treatment. International foumal of Law and Psychiatry 1977;134:279-84.

16 Faulder $\mathrm{C}$. Whose body is it? The troubling issue of informed consent. London Virago, 1985:141.

17 Culver M, Gert B. Philosophy in medicine. Oxford: Oxford University Press, 1982.

18 Dickenson D. Moral luck in medical ethics and practical politics. Aldershot: Gower, 1991:109.

19 Buchanan AE, Brock DW. Deciding for others: the ethics of surrogate decision making. Cambridge: Cambridge University Press, 1989:57.

20 Hsu LKG. The outcome of anorexia nervosa: a re-appraisal. Psychol Med 1988;18:807-12.

21 Steinhausen H-CH, Rauss-Mason C, Seidel R. Follow-up studies of anorexia nervosa: a review of 4 decades of outcome research. Psychol Med 1991;21: 447-54.

(Accepted 25 March 1993)
East Anglian Regional Health Authority, Chesterton, Cambridge J Michael O'Brien, regional director of public health

\section{University of Newcastle-} upon-Tyne Sarah J O'Brien, lecturer in public health medicine

University of Birmingham, Birmingham

Alasdair M Geddes, professor of infection

Norwich Health Authority, Norwich, Norfolk

Bryan J Heap, consultant in communicable disease control

\section{Oxfordshire Health Authority, Oxford Richard T Mayon-White, consultant public health physician}

Correspondence to: Dr O'Brien, East Anglian Regional Health Authority, Union Lane, Chesterton, Cambridge CB4 1RF

BMF 1993;306:1461-4

\title{
Tempting fate: control of communicable disease in England
}

\author{
J Michael O'Brien, Sarah J O’Brien, Alasdair M Geddes, Bryan J Heap, Richard T Mayon-White
}

\begin{abstract}
Recent changes in the NHS have left many defects in the systems for the control of communicable diseases and infection and their surveillance and the management of outbreaks. Clear, explicit legislation is needed, placing the responsibilities on health authorities. New teams led by consultants need to be set up to investigate and manage outbreaks of communicable diseases of all types.
\end{abstract}

"We have an unrivalled system in the UK" for dealing with communicable diseases. So said Baroness Hooper of our arrangements for early warning of outbreaks of communicable disease in a speech to the Institute of Health Service Managers in March $1991 .^{1}$ We believe that our unrivalled system is out of date and needs substantial reforms.

The current surveillance system has three main components. The first is notifications made by doctors attending patients suspected of having certain specified infectious diseases. Notifications are sent to the proper officer of the local authority, who in turn informs the Office of Population Censuses and Surveys. This system is notoriously inaccurate ${ }^{2}$; many doctors not only do not know which diseases are notifiable but also seem unaware of their statutory duty to notify. ${ }^{34}$ This was one of the anxieties of the committee of inquiry into the future development of the public health function (the Acheson Committee) in 1988..$^{5}$ The current list of notifiable diseases is lamentably out of date. ${ }^{6}$ Single cases of diseases which have emerged recently as important problems in public health are not notifiable in England, although, depending on the judgment of individual proper officers about what constitutes a serious outbreak, numbers of cases of these diseases might be brought to the attention of the chief medical officer. ${ }^{7}$

The second source of information is reports of isolates from public health laboratories, hospital laboratories, and a small number of private laboratories. These are collated by the Public Health Laboratory Service/Communicable Disease Surveillance Centre (PHLS/CDSC). The recognition of newly emerging diseases like cryptosporidiosis and legionnaires' disease depends on diagnosis in a laboratory but reporting is voluntary. Concern (so far unsubstantiated) has been expressed that the number of specimens submitted to laboratories might fall with the introduction of the internal market into the NHS, so this important source of epidemiological data might be severely compromised in future.

Thirdly, information about the incidence of communicable diseases is derived from the sentinel scheme run by the Royal College of General Practitioners for reporting disease in general practice. The main drawback of this scheme is that it is patchy. ${ }^{8}$ The best results come from districts in which public health medical staff have established local surveillance including the use of "spotter" general practices.

There are, in addition, separate reporting systems for sexually transmitted diseases, ${ }^{9} \mathrm{HIV}$, and AIDS, ${ }^{10}$ and for new or rare diseases which appear periodically and require the establishment of special surveillance systems.

Two spectacular failures in the investigation and control of outbreaks of communicable diseases in the 1980s at Stanley Royd and Stafford hospitals precipitated the Acheson report, the most comprehensive review of the public health system in England since 1871.

\section{Public health in England: the Acheson report}

The Acheson report made two very important recommendations about the control of communicable disease and infection. The first was that districts should consider appointing full time consultants responsible for communicable disease control who would cover a sufficiently large population to develop and maintain appropriate knowledge. This was commended to authorities in official guidance. ${ }^{11}$

The second recommendation was that the law relating to infectious diseases should be revised "as a matter of urgency" and the Department of Health issued a consultation document in $1989,{ }^{12}$ but sadly no progress has been evident. A Department of Health circular issued after the Acheson report raised expectations ${ }^{11}$ but the responsibilities it suggested still lack any statutory backing. ${ }^{13}$ 


\section{CONTROL OF INFECTIOUS DISEASES}

Local authorities have no legal duty to provide a service for communicable disease control, although they have certain powers under the Public Health (Control of Diseases) Act 1984 and the Public Health (Infectious Disease) Regulations 1988. These two pieces of legislation were substantially consolidation measures, and all the important legislation predates the second world war. Indeed some provisions date back to the sanitary laws of the $1870 \mathrm{~s}$. One of the suggestions in the consultation document was that health authorities and local authorities should share the responsibility for communicable disease control. ${ }^{12}$ But a shared duty would perpetuate the problems of and potential confusion about overall leadership - one of the major criticisms of Acheson.

Sick people look for help from their family doctor, not the environmental health officer. Indeed, patients may be surprised and threatened by a visit from an environmental health officer, who they see as part of an enforcement agency rather than as part of the public health team. The routine investigation of notified infectious diseases is all too often allocated to a technical assistant, who may have little medical or epidemiological knowledge. The investigation is often cursory, covering a few set questions, and important information is often neither recognised nor recorded. The Acheson committee noted that the environmental health officers spend only about $3 \%$ of their time on infectious diseases not transmitted by food. ${ }^{5}$ Although $14 \%$ of their time is spent on food sampling, not all of this activity relates to the control of outbreaks. Neither health authorities nor local authorities have many resources to muster in the face of a large outbreak, but health authorities may be able to recruit members of the community nursing services to help in investigations-provided that both contracts of employment and service contracts permit this flexible use of staff in exceptional circumstances.

\section{Does infection still matter?}

The 1991 series of Reith lectures was concerned with genetics-said to have become more important "now that medicine has almost conquered infectious disease."14 Despite this bold statement it could be argued that communicable diseases and infection taken together still represent one of the biggest causes of avoidable morbidity, although their importance as a cause of mortality has declined. Over the past 10 years they have certainly been important enough to precipitate several major inquiries.

Changes in lifestyle affect the spread of infectious agents. The convenience food industry has developed as a response to the calls of the large number of women now employed outside the home. It has brought unexpected problems as the manufacture and distribution of these foods have created conditions which can favour the growth of micro-organisms.

Salmonellosis is one of the most important food borne infections in Britain ${ }^{15}$ and has a major economic impact in terms of the cost to individual people, the public purse, and industry. ${ }^{16}$ The discovery that the unprecedented increase in the incidence of infection with Salmonella enteritidis phage type 4 was apparently connected with the consumption of chickens and raw egg ${ }^{1718}$ precipitated both national and international inquiries. ${ }^{19} 20$

Campylobacter infection, first described as long ago as $1977,{ }^{21}$ has become the most common bacterial cause of food borne illness, ${ }^{22}$ yet there are considerable gaps in our knowledge of its epidemiology. Other newly recognised food borne illnesses include listeriosis, an infection causing considerable morbidity in pregnancy. Escherichia coli 0157, which is associated with the

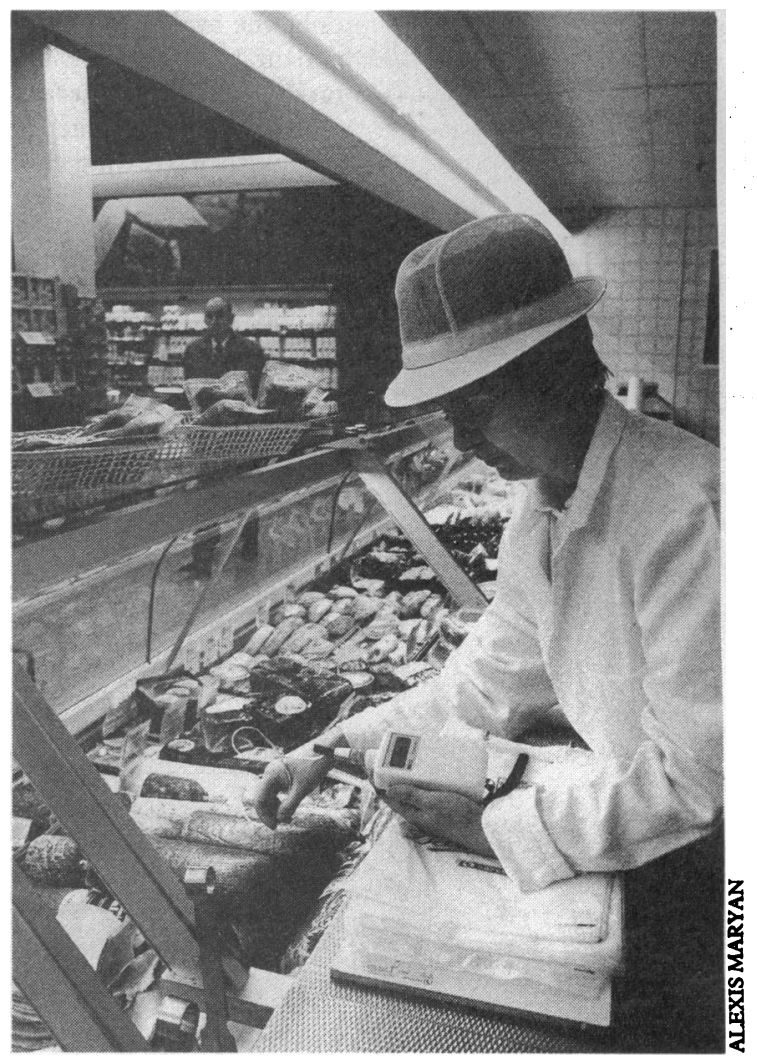

Environmental health officers spend a substantial part of their time in food sampling, but patients do not see them as part of the public health team

haemolytic uraemic syndrome, is now the commonest cause of acute renal failure in childhood. The past decade has witnessed a huge increase in food borne illnesses, which has led to a major review of the microbiological safety of foods. ${ }^{23}$

But food related problems have not been the only concern. The Badenoch inquiry into Cryptosporidium in water supplies ${ }^{24}$ was undertaken as an urgent response to public concern after a large waterborne outbreak of cryptosporidiosis in Swindon and Oxfordshire in $1989 .{ }^{25}$ Social mores have contributed to the rapid and wide spread of HIV unknown before the early 1980 s. $^{26}$

One of the consequences of easier travel abroad has been the importation into this country of infectious agents not normally encountered here. ${ }^{27}$ Infections acquired in hospital cause considerable morbidity and mortality, prolonging the stay of inpatients thereby increasing the costs of care ${ }^{28}$ Recent publicity about Klebsiella reinforces the message. ${ }^{29}$ Organisms with multiple resistance are capable of spreading from hospitals to the community. This changing context of microbiological hazards will undoubtedly continue to unfold. For instance, if the predictions of global warming prove to be correct attention has been drawn to the possible hazards in communicable diseases that will arise..$^{30}$

The nature and distribution of communicable diseases in Britain might have changed substantially during the past century but they have neither disappeared nor declined in importance.

\section{Working for patients and caring for people: or not?}

The NHS and Community Care Act 1990 heralded a fundamental change within the NHS, separating purchasers of health care from providers. Health authorities were recently reminded that communicable disease control is not immune from this process and should be considered in contracts with provider units. $^{31}$ 
In 1991 the Working Group on Communicable Disease Control reported on the development of the posts of consultant in communicable disease control in England. ${ }^{32}$ Although these posts seem to have been widely instituted, they have been established mainly as part time posts-contrary to the recommendations made by the Acheson inquiry and the Galbraith report. ${ }^{33}$ Many posts had not embraced the wider responsibilities associated with communicable disease control and infection, and the subject continues to be marginalised by health authorities. This is disturbing to those of us who had wished to see these consultants committed full time and fully resourced.

The recommendations of the Acheson report still hold good in most respects, but they were not drafted in the context of the NHS market. It was not possible at that time to think of the consultant in communicable disease control as purchaser or provider, a state of affairs subsequently considered in some detail in Yorkshire. ${ }^{34}$ In fact the job of the consultant clearly straddles the purchaser-provider split and does not sit comfortably exclusively on either side. The surveillance and policy functions fit into the purchaser role whereas the executive actions required at the height of an outbreak are more akin to that of the provider. In the context of an outbreak similar to that at Stanley Royd hospital this job is too important to be left to the market. The creation of purchasers and providers with contracts interposed makes for divisions of responsibility-decried by Acheson-in what should be a continuous rapid response service.

One of the requirements of regional health authorities was that they should monitor arrangements in districts. "With the fragmentation of the service into purchasers and providers and more particularly with the establishment of trusts which do not have to account to regions, the regional health authorities are at the very least in an invidious position. Judging by some trust applications the level of understanding of management of the needs of communicable disease control is poor. Once trust status is achieved trusts are beyond the scrutiny of regions and the scrutiny required is beyond the capacity of the management executive outposts. ${ }^{35}$

\section{Where do we go from here?}

We must ensure that the impetus created by the Acheson report is not squandered, causing falling morale in those already undertaking a very important job. Nor should we lose the opportunity to take advantage of the enforced breathing space created by the delay in legislation. To discharge our duty to the public properly and protect them from the ravages of communicable disease we make the following recommendations.

\section{NOTIFICATION}

Firstly, new legislation must be passed soon, updating the list of notifiable diseases to keep pace with the changing face of communicable diseases in this country. We should try, when possible, to harmonise the lists of notifiable communicable diseases across Europe. ${ }^{36}$ Any list of notifiable diseases should be flexible enough to include those which might become endemic in the future. The key to what should be notifiable is the requirement for public health intervention. ${ }^{6}$ Notifications should be routed directly to the consultants in communicable disease control, expediting investigations and avoiding the possibility of important data being delayed.

\section{RESPONSIBILITY}

Secondly, consultation on the review of the law on infectious disease control ${ }^{12}$ showed overwhelming support for giving both local and health authorities a statutory duty for a communicable disease service. ${ }^{37}$ This would have the potential for confirming in statute law the lack of clarity about roles and responsibilities criticised by the Acheson committee.

We recommend that the control of communicable disease and infection in individuals and in the community should be the statutory responsibility of health authorities. The health authorities have the resources and should be encouraged to carry out the initial investigation of cases of notified diseases. This would enable investigations into cases of illness to be conducted in the setting of health care rather than by what is often perceived as an enforcement official of the local authority. Investigators would, under the supervision of the consultant, develop improved skills for epidemiological investigation and might be better placed to facilitate health promotion within the home. Local authorities should retain the duty for the control of premises and processes.

Allied with responsibility there is the issue of accountability. In communicable disease surveillance, work on human investigation which entails interviews, surveys, exclusions, and similar matters must be well directed and promptly carried out, without the interference of conflicting priorities. It must be clear that the consultant has overall responsibility for the control of outbreaks.

\section{KNOWLEDGE}

Thirdly, a clear lead for health authorities in the control of communicable diseases and infection should be supported by a commitment to deploy consultants on a full time basis. The lessons of audit are already confirming the old adage "practice makes perfect." If we expect proficiency in this field we should encourage the development of experts and resource them accordingly. Rather than leaving the consultants in the comparative professional isolation which they suffer at present their capacity to function effectively would be materially enhanced by their assembly into regional or subregional teams with colleagues in microbiology and clinical medicine. They would maintain links with colleagues in other branches of public health medicine; but their method of working in teams with clinicians and pathologists could form a role model for those colleagues. The teams would work closely with colleagues in environmental health departments. In some locations there might be a place for the direct involvement of environmental health officers in the NHS teams. Regions should give a strong lead for consultants to be part of a market regulatory tier with equal access to purchasers and providers. We suspect that this would make life easier for consultants and benefit the population. Incidentally it would relieve other consultants in public health medicine of the burden of providing out of hours cover for which they are not always well equipped.

\section{SURVEILLANCE}

Fourthly, the continued use of laboratory investigations for the purposes of epidemiological surveillance must be supported. There is a danger in the market that this important source of epidemiological material will be lost as it could be argued that it is not "needed." Making laboratory reports a requirement rather than voluntary could help in this respect.

The enormous volume of useful data held in general practice should be better harnessed by formalising the spotter system to supplement that available from improved notification and laboratory reporting.

\section{FUNDING}

Finally, assembly of the staff into infection teams would be resource neutral. It would call for aggrega- 
tion of existing expenditure and top slicing of the funds. Although top slicing is an unpopular practice at present, the economies of scale achieved by concentrating the function into substantial groups would give better value for money. By making the function more visible it would give greater accountability than is evident at present. The only satisfactory alternative to top slicing at regional or subregional level would be the creation of a nationally managed service. Ideally we would prefer to retain the function at regional or subregional level.

\section{Conclusion}

We need a system designed to cope with communicable diseases rather than with a "market," and this requires explicit legislation. Until this is done confusion will continue over responsibilities and powers leaving the public at risk.

1 Hooper G. Europe and health: influencing the centre. London: Institute of Health Service Management, 1991.

2 Haward RA. Scale of under notification of infectious diseases by genera practitioners. Lancet 1973;i:873.

3 Harvey I. Infectious diseases notification-a neglected legal requirement. Health Trends 1991;23:73-4.

4 Voss $S$. How much do doctors know about the notification of infectious diseases? BMF 1992;304:755.

5 The Committee of Inquiry into the Future Development of the Public Health Function. Public Health in England. London: HMSO, 1988. (Acheson report.)

6 Heap BJ. Notifiable diseases. BMF 1992;304:726-7.

7 Public Health (Infectious Diseases) Regulations 1988. London: HMSO, 1988 (SI 1988/1546.)

8 Ashley JSA, Cole SK, Kilbane MP. Health information resources: Unite Kingdom - health and social factors. In: Holland WW, Detels R, Kudx GE eds. Oxford textbook of public health. Vol 2. Methods of public health. Oxford: Oxford University Press, 1991.

9 Venereal Diseases Regulations 1916. London: Local Government Board, 1916.

10 AIDS (Control) Act 1987. London: HMSO, 1987

11 Department of Health. Health services management: health of the population: responsibilities of health authorities. London: $\mathrm{DoH}, 1988$. $(\mathrm{HC}(88) 64$.)

12 Department of Health. Review of law on infectious disease control: consultation document London: DoH, 1989 .
13 Duckworth GJ. Consultants in communicable disease control: currently lacking resources, power and training. BMf 1991;303:483-4.

14 Jones S. The language of the genes. London: British Broadcasting Corporation, 1991. (The 1991 Reith lectures.)

15 Galbraith NS, Barrett NS. Changing patterns of communicable disease. Health

16 Roberts JA, Sockett PN. Economic impact of a nationwide outbreak of salmonellosis: cost benefit of early intervention. $B M 71989 ; 298: 1227-30$

17 Coyle EF, Palmer SR, Ribeiro CD, Jones HI, Howard AJ, Ward L, et al, Salmonella enteritidis phase type 4 infection. Association with hens' eggs. Lancet 1988; ;i: 1295-7.

18 Cowden JM, Lynch D, Joseph CA, O'Mahoney M, Mawer SL, Rowe B, et al. Case-control study of infections with Salmonella enteritidis phase type $\mathbf{4}$ in England. $B M F$ 1989;229:771-3.

19 House of Commons Select Committee on Agriculture. Salmonella in eggs. London: HMSO, 1989.

20 World Health Organisation. Consultation on the epidemiological emergency in poultry and egg salmonellosis. Geneva: WHO, 1989.

21 Skirrow MB. Campylobacter enteritis: a new disease. $B M 7$ 1977;ii:9-11.

22 Cooke EM. Epidemiology of foodborne illness: UK. Lancet 1990;336:790-3.

23 Department of Health. The microbiological safety of food. Parts I and II. Repor of the committee on the microbiological safety of food Lond

of the committee on the microbiological safety of food. London: HMSO, 1990.

wepartment of the Environment, Department of Health. Cryptosporidium
water supplies. London: HMSO, 1990. (Report of the group of experts.)

25 Richardson AJ, Frankenburg RA, Buch AL, Selkon JB, Colbourne JS, Parsons JW, et al An outbreak of water borne cryposporidiosis in Swindon and Oxfordshire. Epidemiol Infect 1991;107:485-96.

26 Centers for Disease Control. Pneumocystis pneumonia-Los Angeles. $M M W R$ 1981;30:250-2

27 Porter JD, Stanwell-Smith R, Lea G. Travelling hopefully, returning ill. $B M$ 1992;304:1323-4.

28 Department of Health. Detection of hospital infection. London: DoH, 1991. (PL (91) CMO/18.)

29 Roberts A. Guy's accused as babies die. The Times 1992;Aug 5:1.

30 Godlee F. Health implications of climate change. BMF 1991;303:1254-6.

31 Department of the Environment, NHS management executive. Communicable disease control. London: $\mathrm{DoE} / \mathrm{DoH}, 1991$. (EL (91) 123.)

32 Faculty of Public Health Medicine. The medical role in communicable diseas control in England: a survey of manpower responsibilities and training. London: FPHM, 1991.

33 Galbraith NS. Consultants in communicable disease control: training needs and provision 1989 to 1996. A report to the chief medical officer. London: $\mathrm{DoH}$ provis

34 Yorkshire Regional Health Authority. Communicable disease control in purchaser/provider context. A report of a working group. Harrogate: YRHA, 1990

35 Greenshields G. NHS trusts: monitoring and accountability arrangement London: DoH, 1991. (Letter to chief executives 21 January 1991.)

36 World Health Organisation. Infectious diseases in Europe: a fresh look. Copenhagen: WHO Regional Office for Europe, 1984

37 Acheson ED. Address to the first national conference for consultants in communicable disease control-June 1991. Health Trends 1991;23:49-50.

(Accepted 9 March 1993)

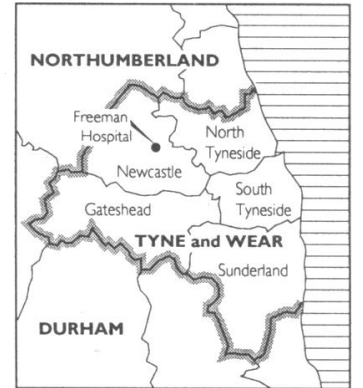

This is the third article in our re-examination of the NHS reforms at the end of their second year

\section{London W4 3BU}

Sharon Kingman, freelance journalist

BMf 1993;306:1464-7

\section{The New NHS: The Second Year}

\section{The Freeman Hospital: disillusionment sets in}

\section{Sharon Kingman}

This time last year the talk at the Freeman Hospital in Newcastle on Tyne was all about treating more patients than its contracts with purchasers specified. ${ }^{1}$ This year it is all about making sure the trust stays within its contracts. Last year there was a sense of pride that the hospital was keeping its beds open when other hospitals all around were closing theirs. This year there is an air of resignation as the trust realises that it has nothing to gain by performing too well. Last year the trust was increasing its staff. This year, there are fears that up to 100 redundancies could be in the offing. And there are plans to reduce the number of acute hospitals in Newcastle from three to two.

\section{Meeting contracts and more}

Around the hospital people voice their frustration at the unfairness of it all. They knuckled down last year, they say, thinking that if they showed willing and treated more patients, their efforts would be rewarded by bigger budgets in the contracts for 1992-3. Yet when those contracts were set staff found that in many cases they were expected to do the same amount of work again-without a corresponding increase in the budgets. The cynics are saying that this was exactly what purchasers meant to happen.
The specialty of internal medicine-rheumatologyprovides an example. Madeleine Rae, the specialty manager, says that in 1991-2 the specialty treated $25-30 \%$ more patients than in the preceding year. Eight months into that financial year internal medicine reported to the trust board that it had already exceeded the level of its contracts by $£ 387000$. Everyone worked very hard, Miss Rae says, in the belief that it would be possible to employ more staff to cope with the extra workload in the following financial year, because the funds attached to the contracts would increase in line with the number of extra patients being treated.

That did not happen. Purchasers did eventually cough up some extra funds for the extra work-but less than the full amount. Internal medicine received only $£ 190000$ towards the shortfall. By the end of the financial year the specialty had managed to reduce the deficit to just $£ 88000$.

Then purchasers set targets for 1992-3 so that the Freeman would have to treat $20 \%$ more patients than in 1990-1 (only slightly fewer than the hospital had actually treated during the bumper year of 1991-2). Miss Rae says, "The assumption was that if we could treat the extra patients in 1991-2 we could do it again the next year. That assumption will now follow us for years. We did all this extra work, and all we have done 